\title{
A cross-sectional study identifying the pattern of factors related to psychological intimate partner violence exposure in Slovenian family practice attendees: what hurt them the most
}

Polona Selic ${ }^{*}$, Igor Svab and Nena Kopcavar Gucek

\begin{abstract}
Background: Intimate partner violence (IPV) is yet to be fully acknowledged as a public health problem in Slovenia. This study aimed to explore the health and other patient characteristics associated with psychological IPV exposure and gender-related specificity in family clinic attendees.

Methods: In a multi-centre cross-sectional study, 960 family practice attendees aged 18 years and above were recruited. In 689 interviews with currently- or previously-partnered patients, the short form of A Domestic Violence Exposure Questionnaire and additional questions about behavioural patterns of exposure to psychological abuse in the past year were given. General practitioners (GPs) reviewed the medical charts of 470 patients who met the IPV exposure criteria. The Domestic Violence Exposure Medical Chart Check List was used, collecting data on the patients' lives and physical, sexual and reproductive, and psychological health status, as well as sick leave, hospitalisation, visits to family practices and referrals to other clinical specialists in the past year. In multivariate logistic regression modelling the factors associated with past year psychological IPV exposure were identified, with $P<0.05$ set as the level of statistical significance.

Results: Of the participants ( $n=470), 12.1 \%(n=57)$ were exposed to psychological IPV in the previous year (46 women and 11 men). They expressed more complaints regarding sexual and reproductive ( $p=0.011)$, and psychological and behavioural status $(p<0.001)$, in the year prior to the survey. Unemployment or working part-time, a college degree, an intimate relationship of six years or more and a history of disputes in the intimate relationship, increased the odds of psychological IPV exposure in the sample, explaining $41 \%$ of the variance. In females, unemployment and a history of disputes in the intimate relationship explained $43 \%$ of the variance.

Conclusions: The prevalence of psychological IPV above 10\% during the past year was similar to earlier studies in Slovenia, although the predominance of better-educated people might be associated with lower tolerance toward psychological abuse. GPs should pay special attention to unemployed patients and those complaining about family disputes, to increase early detection.
\end{abstract}

Keywords: Intimate partner violence, Psychological abuse, Employment status, Disputes in intimate relationship, Level of education

\footnotetext{
* Correspondence: polona.selic@siol.net

Department of Family Medicine, Faculty of Medicine, University of Ljubljana,

Poljanski nasip 58, Ljubljana, Slovenia
}

\section{Ciomed Central}

(c) 2014 Selic et al.; licensee BioMed Central Ltd. This is an Open Access article distributed under the terms of the Creative Commons Attribution License (http://creativecommons.org/licenses/by/2.0), which permits unrestricted use, distribution, and reproduction in any medium, provided the original work is properly credited. The Creative Commons Public Domain Dedication waiver (http://creativecommons.org/publicdomain/zero/1.0/) applies to the data made available in this article unless otherwise stated. 


\section{Background}

There has been increasing recognition in Slovenia of the societal implications of intimate partner violence (IPV), defined as "behaviour within an intimate relationship that causes physical, sexual or psychological harm, including acts of physical aggression, sexual coercion, psychological abuse and controlling behaviours" [1]. The reported prevalence in Slovenia [2-4], as well as a growing body of research on health consequences related to IPV [5-11] and its impact on morbidity and mortality [5], all suggest a gradual change from IPV being seen as a personal and family issue related to the legal and justice system, to an issue that needs to be acknowledged and addressed as a public health problem.

Women have traditionally been considered the victims and men the perpetrators of IPV $[12,13]$; this is probably due to findings that men use more physical force and sexual coercion and are more likely to cause injuries [14-18]. However, women were reported to be more likely to employ psychological aggression [19]. In a limited body of research, it has been suggested that female perpetrators are more likely to suffer from mental health difficulties, especially anxiety and depression [20,21].

Although knowledge of the comparative health effects of different types of IPV is limited, some studies have indicated that victims' exposure to psychological aggression may be more strongly associated with the onset of depression, anxiety, somatisation, and post-traumatic stress disorder than other types of IPV [9,14,20,22-24]. Coker et al. [14] reported both physical and psychological IPV to be associated with significant physical and mental health consequences in victims regardless of gender. Women were significantly more likely than men to experience and report physical or sexual IPV and abuse of power and control, but less likely than men to report verbal abuse alone. For both men and women, being a victim of physical IPV was associated with increased risk of current poor health. In general, abuse of power and control was found to be more strongly associated with adverse health consequences than verbal abuse, and psychological violence was shown to be more damaging to overall health status than physical abuse [14].

In another study, Coker et al. [25] explored the consequences of IPV on physical health and found that women experiencing psychological IPV were significantly more likely to report poor physical and mental health. Psychological IPV was as strongly associated with the majority of adverse health outcomes as physical IPV [25]. Summarising the findings of existing studies, the adverse effects of IPV on women's health should be noted, such as chronic pain $[5,14,26]$, chronic stressrelated symptoms [27] and central nervous system problems [5,14]. Authors worldwide mostly agree in their findings on both the short and long term physical and mental health consequences of IPV exposure [5,28,29]. IPV exposure has been found to be associated with an increase in psychoactive substance use, anxiety, depression, suicidality, and post-traumatic stress disorder symptoms [14,30-36].

Undoubtedly both men's and women's IPV exposure should be explored in IPV research, but the findings need to be interpreted with caution. Psychological abuse has been shown to be the most frequent characteristic of interpersonal violence dynamics, affecting women's health as severely and significantly as other types of abuse $[25,26]$. However, the frequent co-occurrence of psychological aggression with physical violence, as well as difficulties in measurement, combine to reduce certainty with regard to the independent effects of psychological aggression on health. Some recent research showed that more men than women reported exposure to physical assault, while more women reported exposure to sexual coercion in the past year [37]. However, it should be mentioned that studies which found similar levels of IPV in women and men relied largely on past-year estimates or current partners, whereas studies assessing a longer time-frame or including previous partners tended to find dissimilar levels of violence [38]. The risk factors for IPV exposure in a cross-sectional population-based study in Sweden were the present relationship being of at least three years duration for men's exposure, while a young age, lack of social support and being single constituted risk factors for women's IPV exposure [37]. Compared with women who had never been abused, those reporting only psychological abuse were more likely to present negative mental health indicators in a study carried out in Spain [39].

Despite the abundant literature on the consequences of IPV on health, psychological abuse has rarely been considered a relevant health-related problem and has never been studied as such in Slovenia. After reevaluating the prevalence data for past IPV abuse and showing an IPV exposure prevalence of approximately $17 \%$ as a valid estimate [4], it was decided to focus on the separate effects of psychological IPV on family medicine clinic attendees. This study aims to explore the differences between patients who were exposed to psychological IPV in the previous year and those who were not; to identify the health consequences and other patient characteristics associated with this type of IPV exposure; and to examine whether there were any specifically gender-related issues in family clinic attendees.

\section{Methods}

\section{Participants and procedure}

In January 2013, 90 general practitioners (GPs), i.e. family physicians who have finished four years of specialised training, who had already taken part in the 2012 IPV prevalence re-evaluation study [4], were invited to participate in this 
study. Sixty-four of them responded affirmatively (6.7\% GPs listed in the Register of Family Medicine Doctors held in the Medical Chamber of Slovenia). They were provided with written instructions on the approach to the patients and data collection, i.e. the semi-structured interview forms and the medical charts review forms.

\section{The first phase: recruitment of patients}

The first phase of data collection was carried out during the first week of March 2013, when the participating GPs, working in family practices all over the country, asked every fifth family practice attendee aged 18 years and above, regardless of gender, to participate in a study on quality of life. The eligibility criteria for this phase were age, the absence of dementia or even mild cognitive impairment, and the patients' willingness to participate. The aim of the study was not explained, but the subjects were told that participation was not obligatory. Those willing to participate were scheduled for interview within two weeks. This phase of data collection ended either after 15 patients had been recruited, or on March 8, 2013, whichever was the earliest.

\section{The second phase: interviewing the patients}

Of 960 invited patients, 689 interviewees came to family practices during the second phase, which lasted until the end of March. Since research has shown that disclosure of IPV violence is highly influenced by interviewer factors as well as privacy and the context of the interview [40], participating GPs were encouraged to revise the semi- structured interview form prior to interviewing patients, and to contact the coordinating researcher if in need of assistance or consultation.

At the beginning of the interview, the participants were told that exposure to IPV could be considered a serious quality of life issue in adults. After the topic was introduced, they were asked to sign a written consent form. Of the 689 patients, 45 decided against further participation; they were not asked to explain this decision. In total, 644 interviews were carried out and 609 patients declared they had had an intimate partner during the last five years. Those who had not been in an intimate relationship in the previous five year period were excluded from further analysis. A further 109 patients disclosed they had experienced specific acts of psychological abuse earlier in life but not during the past year, and another 30 people stated that they had been exposed to concurrent psychological and physical and/or sexual abuse. The latter group explained that aside from psychological abuse they endured behaviours such as hitting, slapping, kicking, pushing and/or being forced to engage in sexual activities against their will. As the study aimed to analyse solely psychological abuse in patients, those who had experienced psychological IPV during their lifetime but not in the past year were excluded from the analysis. Victims of multiple types of abuse were also excluded from the study, but were offered help and assistance. The drop-out data are presented in Figure 1.

\section{The third phase: auditing patients' medical charts}

After interviewing the patients, GPs reviewed their medical charts $(n=470)$ in the third phase of data collection. The Domestic Violence Exposure Medical Chart Check List from the 2009 study, described in detail elsewhere [2], was used for this purpose.

\section{Participants: study sample}

The final sample consisted of 470 patients, who had been living in an intimate relationship during the past five years, and who had not had previous psychological abuse, or concurrent physical or sexual IPV exposure.

The National Medical Ethics Committee of the Republic of Slovenia approved the protocol of the study (document number 138/02/11).

\section{Measures}

The semi-structured interview form consisted of several questions from the short form of A Domestic Violence Exposure Questionnaire, described by Kopcavar-Gucek et al. [3] and developed in previous studies in Slovenian primary care $[2,41]$. The questions gathered data on gender, age, number of children, marital status, number of divorces and place of residence. To identify psychological IPV adequately, more specific questions with comprehensive, behaviourally-defined descriptions of interpersonal violence events in closed questions were used in the semi-structured interview. The behavioural

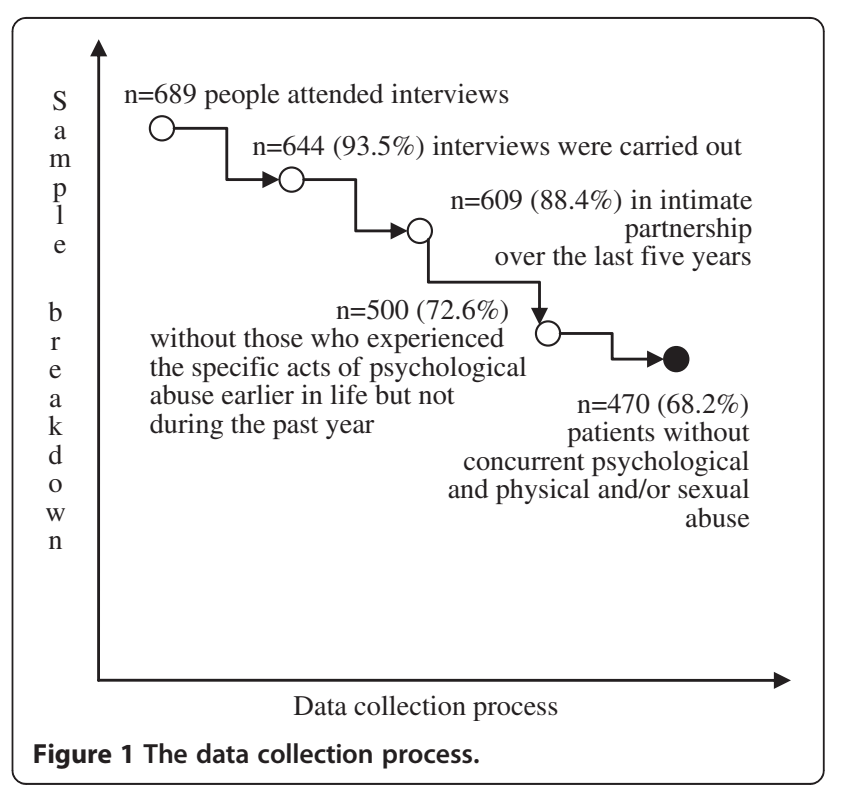


patterns of exposure to psychological violence were also inspired by the work of other authors [39,42]. This also aimed to avoid subjective understanding of the criteria of psychological violence in victims.

For better orientation in time the national holiday March 8, International Women's Day, was used; this timeframe was introduced to patients with questions like: What does March 8 mean to you personally? Do you acknowledge this holiday? What did you do this year? Are you able to recall the March 8 of last year? The patients were told that the subsequent questions were to be considered within this timeframe and were then asked a series of questions: Do you feel safe at home? Do you feel accepted, respected and loved in your intimate relationship? Have you been humiliated, subjected to threats, insult or intimidation, or in any way emotionally affected by your intimate partner? Does your partner talk down to you? Has he/she demeaned or insulted you or made you feel ashamed? Has he/she screamed or cursed at you? Has he/she threatened you with physical harm? If such a thing has happened, have you been thinking about doing something about it? Do you want me to help? Patients were asked to specify whether this had happened in the 12 months preceding the survey, i.e. between March 8, 2012 and March 8, 2013.

These questions had several possible responses (i.e. many times, sometimes, never, not last year, not this year etc.). Participants were considered to have experienced "current psychological abuse" if they answered any question many times or sometimes. Others who answered to each question negatively were marked as negative for current abuse.

The second part of the survey, replicating the procedure of the 2009 study [2], was carried out by the GPs themselves after the interviews. Further information on the participating patients was gathered by auditing medical charts, including data on the patients' wider life context. The physicians analyzed the patients' medical charts and abstracted factors at both the personal level (i.e. alcohol abuse; adult onset of depression; personality disorders; low education level; financial difficulties and instability and unemployment in patient) and at a relationship level [i.e. past experience of violence (domestic violence exposure in primary family) reported by patient and marked in the medical chart; disputes in the intimate partner relationship (i.e. frequent differences of opinion or disagreements, struggles resulting from incompatible or opposing needs, values, demands and/or expectations), reported by patient and noted by the physician; and dysfunctional family relationships (e.g. male dominance in the family as a hardship), already discussed with the patient and marked by the physician], from the whole medical chart. Health-related associations with exposure to IPV were also listed and audited for the previous year (March 2012 to March 2013), and were later categorized into three groups: physical, sexual and reproductive, and psychological. Lastly, sick leave (in episodes and days), hospitalisation (in episodes and days), visits to family clinic and referrals to other clinical specialists in the past year were reviewed, noted and analysed. 'Frequent' among participating patients was defined as within the top 10 centiles in a time frame of one year for each characteristic (Table 1).

\section{Data analysis}

The sample data were presented as frequencies and percentages. Bivariate comparisons were made using the $\chi^{2}$ test or Fisher's exact test. The analysis compared patients who reported having experienced any act of psychological violence in the past year (conceptualised as 'current abuse') with those who did not report any IPV ('current' vs. 'never') (Table 2). Demographic characteristics, the data obtained from patient medical charts for the time prior to the psychological IPV screening period, and current health status variables (see Table 3) were included in the modelling process, but not these without significant bivariate associations with past year psychological IPV exposure (dependent variable). Multivariate logistic regression was used to model those factors associated with past year psychological IPV exposure in the total sample and separately for women only (Tables 4 and 5).

With the aim of avoiding conceptual overlapping between the independent variable disputes in intimate relationship and the dependent variable, another regression

Table 1 Frequent use of health care services during the past year among participating patients

\begin{tabular}{|c|c|c|c|c|c|c|c|}
\hline & \multirow[t]{2}{*}{$\begin{array}{l}\text { Top } 10 \text { centiles (a time } \\
\text { frame of one year) }\end{array}$} & \multicolumn{2}{|c|}{$\begin{array}{l}\text { Psychological } \\
\text { IPV exposure }\end{array}$} & \multirow[t]{2}{*}{$P_{A L L}$} & \multicolumn{2}{|c|}{ Psychological IPV exposure: women } & \multirow[t]{2}{*}{$P_{\text {WOMEI }}$} \\
\hline & & No (N (\%)) & Yes (N (\%)) & & No (N (\%)) & Yes (N (\%)) & \\
\hline Sick leave (episodes) & 3 or more & $44(10.7)$ & $4(7.0)$ & 0.491 & $30(12.4)$ & $4(8.7)$ & 0.621 \\
\hline Sick leave (days) & 46 or more & $43(10.4)$ & $4(7.0)$ & 0.636 & $23(9.5)$ & $4(8.7)$ & 1.000 \\
\hline Hospitalisation (episodes) & 1 or more & $30(7.3)$ & $6(10.5)$ & 0.422 & $13(5.4)$ & $6(13.0)$ & 0.095 \\
\hline Hospitalisation (days) & 1 or more & $30(7.3)$ & $6(10.5)$ & 0.422 & $13(5.4)$ & $6(13.0)$ & 0.095 \\
\hline Visits to family clinic & 16 or more & $40(9.7)$ & $4(7.0)$ & 0.634 & 28 (11.6) & $4(8.7)$ & 0.798 \\
\hline Referrals to other clinical specialists & 5 or more & $37(9.0)$ & $7(12.3)$ & 0.464 & $21(8.7)$ & $5(10.9)$ & 0.582 \\
\hline
\end{tabular}


Table 2 Demographics and health services use in patients

Gender
Male
$\quad$ Female
Age
35 years or less
$36-64$ years
65 years and more
Present marital status
Married or living in an intimate relationship
Widowed
Single

Age of intimate partner

\section{Total N (\%)}

The same or younger

Older

Parenting (children)

No

Single child

Two children or more

Divorce in the past

Yes

No

Place of residence

Rural

Urban

Employment status

Regularly employed

Retired

Unemployed or working part time

Level of education

Elementary school

High school

College or higher

Monthly income per family member

Under average

Average or above

Financial support provided by state

Yes

No

The length of intimate partnership
5 years or less
6 years or more

Alcohol or drug consumption in the family $n=470$

$182(38.7)$

$288(61.3)$

139 (29.6)

254 (54.0)

77 (16.4)

$352(74.9)$

54 (11.5)

64 (13.6)

\section{No $n=413$}

PV exposure $\mathrm{N}(\%)$

Yes $\mathrm{n}=\mathbf{5 7}$

171 (41.4)

$242(58.6)$

$11(19.3)$

$46(80.7)$

$\begin{array}{rr}124(30.0) & 15(29.6) \\ 221(53.5) & 33(57.9) \\ 68(16.5) & 9(15.8)\end{array}$

306 (74.1)

50 (12.1)

57 (13.8)

334 (71.1)

136 (28.9)

126 (26.8)

117 (24.9)

$227(48.3)$

88 (18.7)

$382(81.3)$

53 (11.3)

417 (88.7)

273 (58.1)

119 (25.3)

78 (16.6)

52 (11.1)

203 (43.2)

215 (45.7)

266 (56.6)

204 (43.4)

115 (24.5)

355 (75.5)

165 (35.1)

305 (64.9)

136 (28.9)
301 (72.9)

$112(27.1)$

114 (27.6)

98 (23.7)

201 (48.7)

76 (18.4)

337 (81.6)

47 (11.4)

366 (88.6)

$248(60.0)$

104 (25.2)

61 (14.8)

48 (11.6)

180 (43.6)

185 (44.8)

$232(56.2)$

181 (43.8)

99 (24.0)

314 (76.0)

151 (36.6)

262 (63.4)

$112(27.1)$
0.809

0.471

$46(80.7)$

$4(7.0)$

7 (12.3)

0.028

33 (57.9)

$24(42.1)$

0.252

$12(21.1)$

19 (33.3)

26 (45.6)

0.591

$12(21.1)$

45 (78.9)

1.000

$6(10.5)$

51 (89.5)

0.010

25 (43.9)

15 (26.3)

17 (29.8)

0.416

$$
4(7.0)
$$

23 (40.4)

30 (52.6)

0.670

34 (59.6)

23 (40.4)

16 (28.1)

41 (71.9)

0.078

14 (24.6)

53 (75.4) 
Table 2 Demographics and health services use in patients (Continued)

\begin{tabular}{|c|c|c|c|c|}
\hline No & $334(71.1)$ & $301(72.9)$ & $33(57.9)$ & \\
\hline Sick leave in the past year (episodes) $-M \pm S D$ & $1.1 \pm 2.3$ & $1.1 \pm 2.1$ & $1.2 \pm 3.4$ & 0.114 \\
\hline Sick leave in the past year (days) $-M \pm S D$ & $22.8 \pm 63.2$ & $23.5 \pm 63.6$ & $16.4 \pm 59.8$ & 0.091 \\
\hline Hospitalisation in the past year (episodes) $-\mathrm{M} \pm \mathrm{SD}$ & $0.1 \pm 0.4$ & $0.1 \pm 0.4$ & $0.1 \pm 0.4$ & 0.413 \\
\hline Hospitalisation in the past year (days) $-M \pm S D$ & $1.0 \pm 5.0$ & $1.0 \pm 5.3$ & $0.9 \pm 2.9$ & 0.418 \\
\hline Visits to family clinic in the past year $-M \pm S D$ & $8.2 \pm 5.5$ & $8.3 \pm 5.5$ & $7.6 \pm 5.1$ & 0.465 \\
\hline Referrals to other clinical specialists in the past year $-\mathrm{M} \pm \mathrm{SD}$ & $2.0 \pm 2.2$ & $2.0 \pm 2.2$ & $2.2 \pm 2.3$ & 0.958 \\
\hline Age $-M \pm S D$ & $47.4 \pm 16.1$ & $47.4 \pm 16.2$ & $47.8 \pm 15.6$ & 0.795 \\
\hline
\end{tabular}

Chi-square or Fisher's exact test; Mann-Whitney's $U$ test for continuous data.

modelling was performed without this independent variable, which had been earlier identified as a powerful risk factor for psychological IPV exposure. Similarly, an additional regression modelling was made for female patients without the independent variable disputes in intimate relationship.

The results were presented by crude and adjusted odds ratios with 95\% confidence intervals. Statistical analysis was performed by IBM SPSS 20.0 software (IBM Corp., Armonk, NY, USA), and $P<0.05$ was set as the level of statistical significance.

\section{Results}

Of the sample, $12.1 \%(n=57)$ people had been exposed to psychological IPV in the previous year (46 women and 11 men).

\section{Demographic characteristics of patients}

The average age of all participants $(n=470)$ was $47.4 \pm$ 16.1 years; the average age of men $(n=182)$ was $48.2 \pm$ 15.8 years and of women $(n=288) 46.9 \pm 16.4$ years $(p=$ 0.279 ). The average age of patients without experience of psychological IPV $(\mathrm{n}=413)$ was $47.4 \pm 16.2$ years; men $(\mathrm{n}=171) 48.6 \pm 15.6$ years and women $(\mathrm{n}=242) 46.5 \pm$ 16.6 ( $\mathrm{p}=0.117$ ). People who had been exposed to psychological abuse were $47.8 \pm 15.6$ years old; of them the men were $42.7 \pm 17.7$ and the women $49.0 \pm 15.1$ years old, the latter being seemingly but not significantly older $(\mathrm{p}=0.210)$.

More demographic characteristics of the sample are presented in Table 2.

\section{Frequent use of health care services during the past year among participating patients}

There were no statistically significant differences found between people exposed to psychological IPV and those who did not report such experiences (Table 1).

\section{Patients' medical charts review summary}

In Table 3, the summary of patients' medical charts is presented. Statistically significant differences were identified between the patients exposed and those not exposed to psychological IPV, with regard to muscle inflammations $(\mathrm{p}=0.010)$, sexual and reproductive status in general $(\mathrm{p}=$ 0.011 ), specifically gynaecological disorders and inflammations $(\mathrm{p}=0.011)$, complicated pregnancies/spontaneous abortions $(\mathrm{p}=0.043)$, psychological and behavioural status in general ( $\mathrm{p}<0.001)$, including the onset of depression and/or generalised anxiety disorder $(\mathrm{p}<0.001)$, eating and sleeping disorders $(p=0.042)$, low self-esteem $(p<0.001)$, phobias and panic attacks $(\mathrm{p}=0.001)$, post-traumatic stress disorder $(\mathrm{p}=0.002)$ and psychosomatic disorders $(\mathrm{p}=0.007)$, all assessed or diagnosed by practising GPs in the year prior to the survey.

\section{Associations between psychological intimate partner violence exposure and bio-psycho-social characteristics in patients: logistic regression modelling}

In the regression modelling process, the associations between psychological IPV and the characteristics of patients were explored. Employment status (i.e. unemployed or working part-time) (aOR 5.82, 95\% CI 2.09-16.17, $\mathrm{p}=$ $0.001)$, level of education, i.e. college degree or more (aOR 4.78, 95\% CI 1.09-20.96, $\mathrm{p}=0.038$ ), the length of intimate relationship $\geq 6$ years $(\mathrm{aOR} 4.25,95 \%$ CI 1.01-17.85, $\mathrm{p}=$ 0.048 ) and a history of disputes in the intimate relationship already noted in the patient's medical chart (aOR 13.85, 95\% CI 5.72-33.55, p <0.001) were identified as risk factors, explaining $41 \%$ of the variance (Nagelkerke $\mathrm{R}^{2}=0.413, \mathrm{p}<0.001$ ). More results are presented in Table 4.

In another regression modelling performed without independent variable disputes in intimate relationship, 27\% of the variance was explained $\left(\chi^{2}=73.156, \mathrm{df}=32, \mathrm{p}<\right.$ 0.001 , Nagelkerke $R^{2}=0.276$ ), with employment status (i.e. unemployed or working part-time) (aOR 5.57, 95\% CI 2.23-13.91, $\mathrm{p}<0.001)$ and level of education, i.e. college degree or more (aOR 4.58, 95\% CI 1.22-17.20, $\mathrm{p}=0.024$ ) identified as the sole risk factors. Since the other independent variables were the same as presented in Table 4, the other results of this additional regression analysis are not presented. 
Table 3 Patients' medical charts review summary

\begin{tabular}{|c|c|c|c|}
\hline & $\begin{array}{r}\text { No IPV } \\
\text { exposure } \\
n=413\end{array}$ & $\begin{array}{r}\text { IPV } \\
\text { exposure } \\
n=57\end{array}$ & $p^{*}$ \\
\hline Physical status & $381(92.3 \%)$ & $54(94.7 \%)$ & 0.787 \\
\hline $\begin{array}{l}\text { Injuries: head, thoracic and } \\
\text { abdominal compartment }\end{array}$ & $90(21.8 \%)$ & $12(21.1 \%)$ & 1.000 \\
\hline Scratches and bruises & $162(39.2 \%)$ & $24(42.1 \%)$ & 0.668 \\
\hline Chronic pain syndrome & $324(78.5 \%)$ & $47(82.5 \%)$ & 0.604 \\
\hline Incapacity to work & $87(21.1 \%)$ & $15(26.3 \%)$ & 0.392 \\
\hline Muscle inflammations & $176(42.6 \%)$ & $35(61.4 \%)$ & 0.010 \\
\hline Bone fractures & $92(22.3 \%)$ & $13(22.8 \%)$ & 1.000 \\
\hline Gastrointestinal disorders & $256(62.0 \%)$ & $43(75.4 \%)$ & 0.056 \\
\hline Irregularities in bowel functioning & $187(45.3 \%)$ & $28(49.1 \%)$ & 0.671 \\
\hline Lacerations and cuts & $134(32.4 \%)$ & $18(31.6 \%)$ & 1.000 \\
\hline Eye injuries & $23(5.6 \%)$ & $2(3.5 \%)$ & 0.755 \\
\hline Reduced physical functioning & $41(9.9 \%)$ & $7(12.3 \%)$ & 0.639 \\
\hline Sexual and reproductive status & $201(48.7 \%)$ & $38(66.7 \%)$ & 0.011 \\
\hline $\begin{array}{l}\text { Gynaecological disorders, } \\
\text { inflammations }\end{array}$ & $186(45.0 \%)$ & $36(63.2 \%)$ & 0.011 \\
\hline Infertility & $25(6.1 \%)$ & $4(7.0 \%)$ & 0.768 \\
\hline $\begin{array}{l}\text { Complicated pregnancies/ } \\
\text { spontaneous abortions }\end{array}$ & $55(13.3 \%)$ & $14(24.6 \%)$ & 0.043 \\
\hline Sexual dysfunctions & $14(3.4 \%)$ & $3(3.5 \%)$ & 1.000 \\
\hline $\begin{array}{l}\text { Sexually transmitted diseases } \\
\text { including HIV/AIDS }\end{array}$ & $9(2.2 \%)$ & $2(3.5 \%)$ & 0.631 \\
\hline $\begin{array}{l}\text { Unplanned/unwanted } \\
\text { pregnancies }\end{array}$ & $3(0.7 \%)$ & $1(1.8 \%)$ & 0.405 \\
\hline $\begin{array}{l}\text { Psychological and behavioural } \\
\text { status }\end{array}$ & $346(83.8 \%)$ & $57(100.0 \%)$ & $<0.001$ \\
\hline Abuse of alcohol and drugs & $26(6.3 \%)$ & $3(5.3 \%)$ & 1.000 \\
\hline $\begin{array}{l}\text { The onset of depression and/or } \\
\text { generalised anxiety disorder }\end{array}$ & $272(65.9 \%)$ & $51(89.5 \%)$ & $<0.001$ \\
\hline Eating and sleeping disorders & $151(36.3 \%)$ & $29(50.9 \%)$ & 0.042 \\
\hline Low self-esteem & $173(41.9 \%)$ & $39(68.4 \%)$ & $<0.001$ \\
\hline Phobias and panic attacks & 144 (34.9\%) & $33(57.9 \%)$ & 0.001 \\
\hline Physical inactivity & 149 (36.1\%) & $23(40.4 \%)$ & 0.559 \\
\hline Post-traumatic stress disorder & $148(35.8 \%)$ & $33(57.9 \%)$ & 0.002 \\
\hline Psychosomatic disorders & $292(70.7 \%)$ & $50(87.7 \%)$ & 0.007 \\
\hline Smoking & $90(21.8 \%)$ & $14(24.6 \%)$ & 0.613 \\
\hline Suicidal behaviour and self-harm & $4(1.0 \%)$ & $1(1.8 \%)$ & 0.478 \\
\hline Unsafe sexual behaviour & $1(0.2 \%)$ & $0(0.0 \%)$ & 1.000 \\
\hline
\end{tabular}

*Fisher's exact test (instead of the chi-square for $2 \times 2$ tables).

Associations between psychological intimate partner violence exposure and bio-psycho-social characteristics of female patients: logistic regression modelling

Table 5 presents a logistic regression model of psychological IPV exposure and its associations in female patients. Employment status (i.e. unemployed or working part-time) (aOR 7.82, 95\% CI 2.20-27.85, $\mathrm{p}=0.002$ ) and a history of disputes in the intimate relationship identified by the GP in the patient's medical chart review (aOR 9.12, 95\% CI 3.34-24.89, $\mathrm{p}<0.001$ ) increased the odds of exposure to psychological IPV in female patients, with regression modelling explaining $43 \%$ of the variance (Nagelkerke $\left.\mathrm{R}^{2}=0.431, \mathrm{p}<0.001\right)$.

In an additional regression modelling made for female patients without the independent variable disputes in intimate relationship, 33\% of the variance were explained $\left(\chi^{2}=61.712, \mathrm{df}=31, \mathrm{p}=0.001\right.$, Nagelkerke $\left.\mathrm{R}^{2}=0.330\right)$, and the only risk factor identified was the patient's unemployment or working part-time (aOR 10.48, 95\% CI 3.23-33.97, $\mathrm{p}<0.001)$. All other independent variables were not significantly associated with psychological IPV exposure, so this additional regression modelling is not presented in a table.

\section{Discussion}

The prevalence of psychological IPV of $12.1 \%$ during the past year was similar to the prevalence of $10.3 \%$ found in the 2012 re-evaluation study of Slovenian family medicine attendees [4], regardless of different time period in question (a year $v s$. five years). As stated by Feder et al. [43], asking people about a longer period of time or recent experience can both be potentially problematic; recall bias may be present in responses about a longer period of time, as in the 2012 study [4], while participants in this study, focused on past year violence, might have had insufficient time to acknowledge or identify their abusive experiences as such. It would be fair to conclude that in psychological IPV exposure a prevalence of about $10 \%$ is a correct estimation, although it can still be re-evaluated. This prevalence is also concordant with the findings in the WHO multi-country observational study on women's health and domestic violence [44], which reported that between $4 \%-54 \%$ of respondents were exposed to IPV in the year prior to the survey. It was noted that sampling and the time period in question might have led to differences with respect to the gender symmetry of IPV $[45,46]$. Our findings showed differences in psychological IPV between male and female patients ( $6 \%$ vs. $16 \%$ ) (Table 2). It has been suggested that men generally experience less threatening and less severe forms of IPV, so they may not consider it particularly salient to remember later in life; similarly, given that women are generally exposed to more severe forms of IPV with higher levels of physical injury, coercive control and fear, they may be more likely to report such violence later in life [46]. Since we explored patients' experiences for only one year previous to the data collection, we do not believe that it affected recall in male participants. 
Table 4 Factors associated with intimate partner violence exposure in the previous year

\begin{tabular}{|c|c|c|c|c|c|c|}
\hline & $\begin{array}{l}\text { No IPV } \\
n=413\end{array}$ & $\begin{array}{r}\text { Psych IPV } \\
\mathrm{n}=57\end{array}$ & $\operatorname{cOR}(95 \% \mathrm{Cl})$ & $\mathbf{p}$ & aOR $(95 \% \mathrm{Cl})$ & \\
\hline Female gender & $242(58.6)$ & $46(80.7)$ & $2.96(1.49-5.87)$ & 0.002 & $2.44(0.96-6.18)$ & 0.060 \\
\hline \multicolumn{7}{|l|}{ Marital status } \\
\hline Married or living in intimate partnership & $306(74.1)$ & $46(80.7)$ & 1.00 (reference) & & 1.00 (reference) & \\
\hline Widowed & $50(12.1)$ & $4(7.0)$ & $0.53(0.18-1.54)$ & 0.245 & $0.90(0.15-5.32)$ & 0.905 \\
\hline Single & $57(13.8)$ & $7(12.3)$ & $0.82(0.35-1.90)$ & 0.639 & $1.06(0.19-5.85)$ & 0.949 \\
\hline Divorce in the past & $76(18.4)$ & $12(21.1)$ & $1.18(0.60-2.34)$ & 0.631 & $0.69(0.25-1.88)$ & 0.468 \\
\hline Living in urban setting & $366(88.6)$ & $51(89.5)$ & $1.09(0.44-2.68)$ & 0.849 & $1.09(0.35-3.37)$ & 0.877 \\
\hline \multicolumn{7}{|l|}{ Employment status } \\
\hline Regularly employed & $248(60.0)$ & $25(43.9)$ & 1.00 (reference & & 1.00 (reference) & \\
\hline Retired & $104(25.2)$ & $15(26.3)$ & $1.43(0.73-2.82)$ & 0.302 & $2.18(0.66-7.13)$ & 0.199 \\
\hline Unemployed or working part time & $61(14.8)$ & $17(29.8)$ & $2.77(1.41-5.44)$ & 0.003 & $5.82(2.09-16.17)$ & 0.001 \\
\hline \multicolumn{7}{|l|}{ Level of education } \\
\hline Elementary school & $48(11.6)$ & $4(7.0)$ & 1.00 (reference & & 1.00 (reference) & \\
\hline High school & $180(43.6)$ & $23(40.4)$ & $1.53(0.51-4.65)$ & 0.450 & $2.30(0.58-9.14)$ & 0.237 \\
\hline College degree or more & $185(44.8)$ & $30(52.6)$ & $1.95(0.65-5.79)$ & 0.231 & $4.78(1.09-20.96)$ & 0.038 \\
\hline Below-average monthly income per family member & $232(56.2)$ & $34(59.6)$ & $1.15(0.66-2.03)$ & 0.620 & $0.95(0.39-2.28)$ & 0.904 \\
\hline Financial support provided by state & $99(24.0)$ & $16(28.1)$ & $1.24(0.67-2.30)$ & 0.500 & $1.35(0.55-3.34)$ & 0.511 \\
\hline The length of intimate relationship $\geq 6$ years & $262(63.4)$ & $43(75.4)$ & $1.77(0.94-3.34)$ & 0.078 & $4.25(1.01-17.85)$ & 0.048 \\
\hline Alcohol or drug consumption in the family & $112(27.1)$ & $24(42.1)$ & $1.96(1.11-3.45)$ & 0.021 & $1.55(0.71-3.37)$ & 0.272 \\
\hline \multicolumn{7}{|l|}{ Age } \\
\hline 35 years or less & $124(30.0)$ & $15(26.3)$ & 1.00 (reference & & 1.00 (reference) & \\
\hline $36-64$ years & $221(53.5)$ & $33(57.9)$ & $1.23(0.65-2.36)$ & 0.525 & $0.92(0.31-2.74)$ & 0.885 \\
\hline 65 years or more & $68(16.5)$ & $9(15.8)$ & $1.09(0.46-2.63)$ & 0.841 & $1.03(0.19-5.49)$ & 0.976 \\
\hline \multicolumn{7}{|l|}{ Parenting } \\
\hline No & $114(27.6)$ & $12(21.1)$ & 1.00 (reference) & & 1.00 (reference) & \\
\hline One child & $98(23.7)$ & 19 (33.3) & $1.84(0.85-3.98)$ & 0.121 & $0.68(0.19-2.40)$ & 0.547 \\
\hline Two children or more & $201(48.7)$ & $26(45.6)$ & $1.23(0.60-2.53)$ & 0.576 & $0.51(0.14-1.88)$ & 0.315 \\
\hline Older intimate partner & $112(27.1)$ & $24(42.1)$ & $1.96(1.11-3.45)$ & 0.021 & $1.88(0.80-4.42)$ & 0.150 \\
\hline Patient's MCR: personality disorders & $26(6.3)$ & $7(12.3)$ & $2.08(0.86-5.05)$ & 0.104 & $0.88(0.29-2.72)$ & 0.828 \\
\hline Patient's MCR: domestic violence exposure in primary family & $103(24.9)$ & $23(40.4)$ & $2.04(1.15-3.62)$ & 0.015 & $1.35(0.60-3.06)$ & 0.466 \\
\hline Patient's MCR: history of disputes in intimate relationship & $104(25.2)$ & $46(80.7)$ & $12.436 .21-24.88)$ & $<0.001$ & $13.85(5.72-33.55)$ & $<0.001$ \\
\hline Patient's MCR: financial difficulties and instability & $227(55.0)$ & $44(77.2)$ & $2.77(1.45-5.30)$ & 0.002 & $1.22(0.46-3.27)$ & 0.686 \\
\hline Patient's MCR: dysfunctional family relations & $189(45.8)$ & $42(73.7)$ & $3.32(1.78-6.17)$ & $<0.001$ & $1.37(0.59-3.18)$ & 0.467 \\
\hline Patient's MCR: history of unemployment & $130(31.5)$ & $26(45.6)$ & $1.82(1.04-3.20)$ & 0.035 & $0.66(0.26-1.68)$ & 0.386 \\
\hline Patient's MCR: muscular inflammations & $176(42.6)$ & $35(61.4)$ & $2.14(1.21-3.78)$ & 0.009 & $1.18(0.56-2.52)$ & 0.662 \\
\hline Patient's MCR: gynaecological disorders, inflammations & $137(33.2)$ & $34(59.6)$ & $2.98(1.69-5.25)$ & $<0.001$ & $0.98(0.43-2.24)$ & 0.959 \\
\hline $\begin{array}{l}\text { Patient's MCR: complications during pregnancy/spontaneous } \\
\text { abortions }\end{array}$ & $55(13.3)$ & $13(22.8)$ & $1.92(1.09-4.13)$ & 0.060 & $1.07(0.36-3.17)$ & 0.909 \\
\hline $\begin{array}{l}\text { Patient's MCR: the onset of depression and/or generalised } \\
\text { anxiety disorder }\end{array}$ & $272(65.9)$ & $51(89.5)$ & $4.41(1.85-10.52)$ & 0.001 & $1.39(0.37-5.23)$ & 0.630 \\
\hline Patient's MCR: eating and sleeping disorders & $151(36.6)$ & $29(50.9)$ & $1.80(1.03-3.14)$ & 0.039 & $0.93(0.42-2.03)$ & 0.849 \\
\hline Patient's MCR: phobias and panic attacks & $144(34.9)$ & $33(57.9)$ & $2.57(1.46-4.51)$ & 0.001 & $2.30(0.97-5.44)$ & 0.057 \\
\hline Patient's MCR: low level of self-esteem: Expressing shame & $173(41.9)$ & $39(68.4)$ & $3.01(1.66-5.43)$ & $<0.001$ & $1.32(0.53-3.31)$ & 0.550 \\
\hline
\end{tabular}


Table 4 Factors associated with intimate partner violence exposure in the previous year (Continued)

\begin{tabular}{lllllll}
\hline Patient's MCR: post-traumatic stress disorder & $148(35.8)$ & $33(57.9)$ & $2.46(1.40-4.32)$ & 0.002 & $0.80(0.33-1.97)$ & 0.632 \\
Patient's MCR: psychosomatic disorders & $292(70.7)$ & $50(87.7)$ & $2.96(1.31-6.71)$ & 0.009 & $0.63(0.19-2.10)$ & 0.451 \\
\hline
\end{tabular}

COR: crude odds ratio.

aOR: adjusted odds ratio - adjusted for age, gender, and all other independent variables in the table. Patient's MCR: Patient's Medical Chart Review.

A Logistic Regression Model: $X^{2}=114.112, \mathrm{df}=33, \mathrm{p}<0.001$, Nagelkerke $\mathrm{R}^{2}=0.413$.

\section{Associations between psychological intimate partner violence exposure and health status and the use of health care services}

Given that psychological abuse often precedes physical abuse [27], and has been found to be as strongly associated with the majority of adverse health outcomes as physical IPV [25], the findings of this study could serve as a useful tool for GPs to aid improved detection of psychological IPV and proper early intervention, although people exposed to psychological IPV have not been shown to use health care services more (Tables 1 and 2).

The incidence of several, mostly psychological and behavioural status-related conditions (e.g. depression and anxiety, eating and sleeping disorders, low self-esteem, phobias and panic attacks, post-traumatic stress disorder (PTSD), psychosomatic disorders), was found to be significantly higher in psychologically abused patients' medical charts review (Table 3), which is concordant with the findings of other authors [47-50]. Psychological IPV was found to be as detrimental as physical IPV in terms of depressive symptoms [51], and also to be a significant predictor of higher levels of IPV-related depression [52]. Women reporting IPV have been shown to be significantly more likely to experience a greater degree of depressive symptoms and functional impairment with lower selfesteem and life satisfaction at five-year follow up [53]. A history of IPV was also found to be positively associated with increased incidence of PTSD symptoms, PTSD diagnoses [54,55], and increased levels of anxiety in women $[47,54,56,57]$. An association between the severity of anxiety symptoms and co-occurring depression has also been reported, with the severity of anxiety being higher in abused women with depressive symptoms [51]. As expected, gynaecological disorders were more prevalent in the emotionally abused participants of this study (Table 3), since gynaecological symptoms were also reported to be associated with a history of IPV in many other studies [58-60].

However, all of these health conditions were not significantly associated with psychological IPV exposure in multivariate modelling procedures used to partition the variance in a wide variety of indicators of participants' experiences (Tables 4 and 5). When discussing these results, adjusted odds ratios (aOR) between $0.95>\mathrm{OR}<$ $1.05(\mathrm{p}<0.05)$ were considered as indicative of no association and aORs of 1.05 or greater $(\mathrm{p}<0.05)$ as risk factors for psychological IPV exposure. In case of aORs of 0.95 or less, with $\mathrm{p}<0.05$ set as the level of statistical significance, we would have been discussing protective factors for IPV. However, there were none identified. The term risk factor is used loosely to indicate the direction of association with IPV rather than to imply causality, as we have been analysing mainly cross-sectional data.

Regardless of gender, most variation was associated with employment status, level of education, an intimate relationship of longer than six years, and a history of disputes in the intimate relationship (Table 4), while in women, unemployment and a history of disputes in the intimate relationship, identified by the GP in the patient's medical chart review, were also identified as risk factors for psychological IPV exposure (Table 5). Apart from a college degree, identified as a risk factor in the whole sample, we believe that unemployment, which increases the odds of being exposed to psychological IPV by over five times, could also be considered as a risk factor for the onset of depression and/or anxiety, as diagnosed in $89.5 \%(\mathrm{p}<0.001)$ of IPV-exposed subjects (Table 3). Otherwise, apart from a genetic predisposition and stressful life events, the known risk factor for depression is a lower socioeconomic status (unemployment rate, lower education, poverty) $[61,62]$. The literature review by Kessler et al. [63] is consistent in showing a strong comorbidity between general anxiety disorder and adult onset of depression, which was the reason we constructed a single variable for the analysis, i.e. The onset of depression and/or generalised anxiety disorder in the medical history (Tables 3, 4 and 5). In Slovenia, Klemenc Ketis et al. [64] reported a prevalence of $15.2 \%$ patients with depression in the adult population aged between 18 and 64 years. The incidence of depression and/or anxiety in our sample was apparently higher; however, it needs to be further tested in IPV exposed patients at least once more before any valid conclusions can be drawn.

\section{The harmful impact of employment status}

In the first quarter of 2012, at the time period in question for this study, the registered unemployment rate, defined as the percentage of unemployed people in the labour force in Slovenia, was 12.3\% [65]. In the last four years, the number of employed people in the country 
Table 5 Factors associated with intimate partner violence exposure in the previous year in female patients

\begin{tabular}{|c|c|c|c|c|c|c|}
\hline & $\begin{array}{l}\text { No IPV } \\
n=242\end{array}$ & $\begin{array}{l}\text { Psych IPV } \\
n=46\end{array}$ & cOR $(95 \% \mathrm{Cl})$ & $\mathrm{p}$ & aOR $(95 \% \mathrm{Cl})$ & $\mathrm{p}$ \\
\hline Female gender & & & & - & & - \\
\hline \multicolumn{7}{|l|}{ Marital status } \\
\hline Married or living in intimate partnership & $172(71.1)$ & $38(82.6)$ & 1.00 (reference) & & 1.00 (reference) & \\
\hline Widowed & $38(15.7)$ & $4(8.7)$ & $0.48(0.16-1.42)$ & 0.182 & $0.60(0.08-4.31)$ & 0.613 \\
\hline Single & $32(13.2)$ & $4(8.7)$ & $0.57(0.19-1.70)$ & 0.309 & $0.40(0.05-3.02)$ & 0.373 \\
\hline Divorce in the past & $50(20.7)$ & $12(26.1)$ & $1.36(0.65-2.81)$ & 0.413 & $1.06(0.31-3.56)$ & 0.929 \\
\hline Living in urban setting & $217(89.7)$ & $41(89.1)$ & $0.95(0.34-2.61)$ & 0.913 & $0.84(0.22-3.24)$ & 0.805 \\
\hline \multicolumn{7}{|l|}{ Employment status } \\
\hline Regularly employed & $151(62.4)$ & $20(43.5)$ & 1.00 (reference) & & 1.00 (reference) & \\
\hline Retired & $63(26.0)$ & $12(26.1)$ & $1.44(0.66-3.12)$ & 0.357 & $1.71(0.41-7.07)$ & 0.458 \\
\hline Unemployed or working part time & $28(11.6)$ & $14(30.4)$ & $3.78(1.71-8.34)$ & 0.001 & $7.82(2.20-27.85)$ & 0.002 \\
\hline \multicolumn{7}{|l|}{ Level of education } \\
\hline Elementary school & $27(11.2)$ & $4(8.7)$ & 1.00 (reference) & & 1.00 (reference) & \\
\hline High school & $103(42.6)$ & $20(43.5)$ & $1.31(0.41-4.16)$ & 0.646 & $1.55(0.31-7.69)$ & 0.593 \\
\hline College degree or more & $112(46.3)$ & $22(47.8)$ & $1.33(0.42-4.17)$ & 0.629 & $2.02(0.38-10.80)$ & 0.411 \\
\hline Below-average monthly income per family member & $137(56.6)$ & $29(63.0)$ & $1.31(0.68-2.51)$ & 0.419 & $1.34(0.47-3.87)$ & 0.587 \\
\hline Financial support provided by state & $62(25.6)$ & $11(23.9)$ & $0.91(0.44-1.91)$ & 0.807 & $1.13(0.37-3.51)$ & 0.829 \\
\hline The length of intimate relationship $\geq 6$ years & $142(58.7)$ & $35(76.1)$ & $2.24(1.09-4.62)$ & 0.029 & $2.75(0.63-12.08)$ & 0.181 \\
\hline Alcohol or drug consumption in the family & $65(26.9)$ & $22(47.8)$ & $2.50(1.31-4.76)$ & 0.005 & $2.33(0.92-5.94)$ & 0.075 \\
\hline \multicolumn{7}{|l|}{ Age } \\
\hline 35 years or less & 79 (32.6) & $11(23.9)$ & 1.00 (reference) & & 1.00 (reference) & \\
\hline $36-64$ years & $125(51.7)$ & $28(60.9)$ & $1.61(0.76-3.41)$ & 0.215 & $1.32(0.36-4.87)$ & 0.673 \\
\hline 65 years or more & $38(15.7)$ & $7(15.2)$ & $1.32(0.48-3.68)$ & 0.592 & $1.06(0.13-8.51)$ & 0.956 \\
\hline \multicolumn{7}{|l|}{ Parenting } \\
\hline No & $60(24.8)$ & $8(17.4)$ & 1.00 (reference) & & 1.00 (reference) & \\
\hline One child & $67(27.7)$ & $17(37.0)$ & $1.90(0.77-4.73)$ & 0.166 & $0.80(0.16-4.01)$ & 0.785 \\
\hline Two children or more & $115(47.5)$ & $21(45.7)$ & $1.37(0.57-3.28)$ & 0.480 & $0.51(0.10-2.64)$ & 0.425 \\
\hline Older intimate partner & $101(41.7)$ & $22(47.8)$ & $1.28(0.68-2.41)$ & 0.445 & $1.35(0.53-3.46)$ & 0.532 \\
\hline Patient's MCR: personality disorders & $13(5.4)$ & $5(10.9)$ & $2.15(0.73-6.35)$ & 0.167 & $0.85(0.20-3.59)$ & 0.824 \\
\hline $\begin{array}{l}\text { Patient's MCR: domestic violence exposure in primary } \\
\text { family }\end{array}$ & $67(27.7)$ & $17(37.0)$ & $1.53(0.79-2.97)$ & 0.207 & $0.82(0.31-2.19)$ & 0.690 \\
\hline $\begin{array}{l}\text { Patient's MCR: history of disputes in intimate } \\
\text { relationship }\end{array}$ & $64(26.4)$ & $37(80.4)$ & $11.43(5.23-25.01)$ & $<0.001$ & $9.12(3.34-24.89)$ & $<0.001$ \\
\hline Patient's MCR: financial difficulties and instability & $128(52.9)$ & $37(80.4)$ & $3.66(1.69-7.92)$ & 0.001 & $1.45(0.41-5.09)$ & 0.567 \\
\hline Patient's MCR: dysfunctional family relations & $113(46.7)$ & $36(78.3)$ & $4.11(1.95-8.66)$ & $<0.001$ & $2.35(0.78-7.04)$ & 0.127 \\
\hline Patient's MCR: history of unemployment & $70(28.9)$ & $20(43.5)$ & $1.89(0.99-3.61)$ & 0.053 & $0.44(0.15-1.30)$ & 0.137 \\
\hline Patient's MCR: muscular inflammations & $101(41.7)$ & $28(60.9)$ & $2.17(1.14-4.14)$ & 0.018 & $1.20(0.51-2.85)$ & 0.673 \\
\hline Patient's MCR: gynaecological disorders. inflammations & $137(56.6)$ & $34(73.9)$ & $2.17(1.07-4.40)$ & 0.031 & $1.67(0.58-4.80)$ & 0.339 \\
\hline $\begin{array}{l}\text { Patient's MCR: complications during pregnancy/spontaneous } \\
\text { abortions }\end{array}$ & $55(22.7)$ & $13(28.3)$ & $1.34(0.66-2.72)$ & 0.419 & $0.61(0.18-2.12)$ & 0.437 \\
\hline $\begin{array}{l}\text { Patient's MCR: the onset of depression and/or generalised } \\
\text { anxiety disorder }\end{array}$ & $160(66.1)$ & $42(91.3)$ & $5.38(1.87-15.53)$ & 0.002 & $1.25(0.22-7.01)$ & 0.797 \\
\hline Patient's MCR: eating and sleeping disorders & $93(38.4)$ & $24(52.2)$ & $1.75(0.93-3.29)$ & 0.084 & $1.13(0.45-2.81)$ & 0.792 \\
\hline \multirow[t]{2}{*}{ Patient's MCR: phobias and panic attacks } & $84(34.7)$ & $26(56.5)$ & $2.45(1.29-4.64)$ & 0.006 & $1.59(0.59-4.29)$ & 0.360 \\
\hline & $100(41.3)$ & $33(71.7)$ & $3.61(1.81-7.19)$ & $<0.001$ & $1.27(0.42-3.84)$ & 0.667 \\
\hline
\end{tabular}


Table 5 Factors associated with intimate partner violence exposure in the previous year in female patients (Continued)

\begin{tabular}{|c|c|c|c|c|c|c|}
\hline \multicolumn{7}{|c|}{$\begin{array}{l}\text { Patient's MCR: low level of self-esteem: expressing shame } \\
\text { and guilt }\end{array}$} \\
\hline Patient's MCR: post-traumatic stress disorder & $85(35.1)$ & $27(58.7)$ & $2.63(1.38-5.00)$ & 0.003 & $0.83(0.28-2.43)$ & 0.731 \\
\hline Patient's MCR: psychosomatic disorders & $174(71.9)$ & $42(91.3)$ & $4.10(1.42-11.88)$ & 0.009 & $0.82(0.18-3.65)$ & 0.793 \\
\hline
\end{tabular}

cOR: crude odds ratio.

aOR: adjusted odds ratio - adjusted for age and all other independent variables in the table.

Patient's MCR: Patient's Medical Chart Review.

A Logistic Regression Model: $X^{2}=83.530, \mathrm{df}=32, \mathrm{p}<0.001$, Nagelkerke $\mathrm{R}^{2}=0.431$.

was reduced by 70000, while the population of unemployed has grown by 39000; of these, approximately one half was younger than 35 years [65]. In our study, $16.6 \%$ of people were unemployed or working part-time (Table 2$)$, and the percentage is significantly higher $(\mathrm{p}=$ $0.010)$ in IPV-exposed people (29.8\%) compared to those not exposed (14.8\%); this data obviously shows the unemployment of the study participants as being above the national rate. The official rate of unemployment in this country has been growing from $10.7 \%$ in 2010 to $13.6 \%$ in 2013, and the trend is expected to continue [65], which should be considered a threat to the well-being of the general population in Slovenia. Unemployment in women and in general was identified as a powerful risk factor for psychological IPV exposure in this study, presumably associated with poverty or at least with the threat thereof. Violence was reported to be frequently used with the aim of resolving conflicts caused by poverty [23].

\section{Intimate partnership characteristics and educational attainment as risk factors}

A history of disputes in the intimate relationship was shown to be the most powerful risk factor (Tables 4 and 5). As stated by Jewkes [66], relationships full of conflict, especially those in which conflicts occur about finance, jealousy, and women's gender role transgressions, are more likely to be violent. Educationally, economically, and socially empowered women were found to be the most protected, the relation between empowerment and risk of IPV being presented as non-linear [66]. Contrary to this, in our study sample, a college degree increased the odds of psychological abuse (Table 4). On 1 January 2012, 19\% of Slovenian citizens had tertiary education, i.e. a college degree or higher. Among the employed population, 29\% had attained this level of education, while the proportion of highly educated people in the unemployed population was $14 \%$ at that time [67]. Of the participants in this study (Table 2), $45.7 \%$ people had attained a college degree or higher; in those exposed to IPV this rate was $52.6 \%$, while among those not exposed it was $44.8 \%(\mathrm{p}=0.416)$. This rate is apparently well above the national average. Aside from formal marriage, the WHO multi-country study on women's health and domestic violence showed secondary education and a high socio-economic status to be protective factors for IPV exposure [68]. The increased likelihood of better educated participants being exposed to psychological abuse in this study (Table 4) could be explained by their perception and sensibility toward IPV-related behaviour. Whether or not it is reasonable to expect bettereducated people to be less tolerant of psychological IPV due to their increased knowledge, norms, values and expectations, is yet to be discovered. Further exploration, probably based on a qualitative approach, would be needed to test this hypothesis.

Since conflicts and disputes in the intimate relationship could have been perceived and interpreted by the patients as psychological IPV itself, additional modelling was performed and employment status identified as a risk factor in both the whole sample and in women only. Aside from the risk factors already discussed, the length of the intimate relationship ( $\geq 6$ years - Table 4$)$ increased the odds of participants being exposed to psychological IPV, similarly to other findings [37]. However the same was not identified in female patients analysed separately, and although somehow understandable, it needs further verification.

\section{Implications for family practice and future research}

Generally, the sample in this study could not be considered as representative of a family medicine attendees' population. In comparison to a representative sample of Slovenian family practice attendees [69], in our sample there were more women $(61.3 \%$ vs. $54.8 \%)$, the mean age was slightly younger ( $47.4 \pm 16.1$ years $v s .51 .7 \pm 19.0)$, and level of education higher $(45.7 \%$ vs. $11.3 \%$ people with college degree or above, $11.1 \%$ vs. $41.0 \%$ with elementary school).

Our results failed to demonstrate that psychological IPV alone is highly detrimental to patients' health, as has been suggested by others [54]. Possible explanation might have been difficulties in managing ethical dilemmas in Slovenian family medicine, given that Klemenc-Ketis et al. [70] found one of the most difficult ethical issues for GPs to be suspicion of physical abuse, sexual abuse, or other criminal behaviour exposure in patients. However, we believe one of the main reasons for our findings was the time period, i.e. current exposure. Moreover, the results are important, as psychological IPV is often still considered a 
minor type of violence in Slovenia, and consequently receives less attention than physical IPV from clinicians, lawyers, policy makers, researchers and the female victims themselves. Thus, exposure to psychological IPV alone should no longer be considered a minor type of IPV in family medicine practices. More importantly, as stated by Blasco-Ros et al. [54], psychological IPV alone should be considered as less likely to cease than physical IPV or concurrent psychological and physical IPV. Therefore our advice for GPs would be to consider the possibility of exposure to psychological IPV alone in patients who have persistent complaints regarding their psychological and behavioural status (Table 3).

The cross-sectional survey design is inherently limited and, together with reliance on self-reported data, raises questions about the potential for method variance to account for our findings. However, the phenomenon being studied could have been assessed only by asking patients to report their experience or perception, and it was advantageous that this research design incorporated medical records to obtain the exact health related data (marked as Patient's Medical Chart Review - see Tables 3, 4 and 5). Aside from the self-reported data, several characteristics were followed through the longer period of time reviewed by the GPs in the patients' medical history, which we consider mitigated the potential effects of method variance. In the modelling process, data obtained from patients' medical charts for the time prior to psychological IPV screening period and current health status variables were included. This allowed us to explore the effects of early-life characteristics and experiences. Although there were a few factors identified as being associated with psychological IPV exposure, and none of them could be considered as a medical condition, the advantage of this study is the partition of the explained variance ( $41 \%$ and $43 \%$ respectively). Our finding that health status data from the previous year were not associated with the current psychological IPV exposure suggests the importance of taking this time frame into account when assessing psychological IPV-related health conditions. Prospective studies using clear diagnostic criteria and measures, as well as in-depth, qualitative studies, would be beneficial for extending and deepening our understanding of bio-psycho-social patterns in psychological IPV-exposed patients. We believe that further research should also focus on a longer period of time in order to get more concise characteristics and better grounds for preventive action planning at the societal level and also in the field of family medicine in Slovenia.

\section{Limitations to the study}

Data on each GP's drop-out rate (i.e. the response rate from the first to the second phase of recruitment of patients) was not analysed. Of 960 scheduled patients, 689 (71.8\%) attended the interview. One of the reasons for this first drop-out could have been eligibility criteria at the first phase of data collection, i.e. age, the absence of dementia or even mild cognitive impairment, and patients' willingness to participate. Since patients coming for administrative purposes, i.e. chronic patients coming for prescriptions and patients requiring sick leave forms, were also included, their need for health care services could have been fulfilled by getting what they had come for, so later there was no intrinsic motivation for them to attend the scheduled interviews. We believe that the recruitment capacity of GPs could also have been associated with the quality of their relationships with the patients.

The question of the validity of GPs' assessment of psychological and behavioural status and its components (Tables 3, 4 and 5) should also be raised. For the time being, it remains unclear whether or not the onset of depression and/or generalised anxiety disorder, eating and sleeping disorders, phobias and panic attacks, post-traumatic stress disorder and psychosomatic disorders were diagnosed as meeting all relevant criteria and guidelines.

Finally, the already-mentioned disadvantage that our findings are not based on a representative sample of family practice attendees in Slovenia should be considered a serious limitation; therefore the identified risk factors could serve as relatively valid guidance for family physicians only in middle-aged, better educated and predominantly female patients.

\section{Conclusions}

The prevalence data of psychological IPV exposure in $12.1 \%$ of people are concordant with our previous findings in Slovenia. In the sample, the predominance of better-educated people might have been associated with lower tolerance towards psychological IPV. Unemployment in patients should be taken seriously in family medicine attendees, if GPs want to recognise psychological IPV and intervene effectively in individual cases. The state of economical and societal affairs in a country where the unemployment rate is still growing must be acknowledged, and GPs should strengthen their role as their patients' advocates in the broadest meaning of bio-psychosocial well-being.

The results of this study, although aimed at exploring gender-related patterns of psychological IPV, warn of the possible damaging impact of employment status, based on prospective data in patients' medical charts. It could be of utmost importance since psychological abuse often precedes other forms of interpersonal violence.

\section{Abbreviations}

GP: A family physician who has finished four years of specialised training; COR: Crude odds ratio; aOR: Adjusted odds ratio; Patient's MCR: Patient's Medical Chart Review. 


\section{Competing interests}

The authors declare that they have no competing interests.

\section{Authors' contributions}

PS conceived the study and drafted the manuscript. IS participated in interpretation and helped to draft the manuscript. NKG carried out the execution of the study. All the authors read and approved the final manuscript.

\section{Authors' information}

PS: Ph.D. Clinical Psychology, Senior Researcher and Associate Professor at the Department of Family Medicine. IS: Ph.D. Family Medicine, Professor, Head of the Department of Family Medicine, NKG: Ph.D. student.

\section{Acknowledgements}

We are grateful to the GPs and patients who took part in the study. Special thanks to Mr. Alojz Tapajner for his efforts with data and Ms. Justi Carey for her language corrections. The study was partly supported by the Slovenian Research Agency, Research Programme Code P3-0339.

Received: 28 November 2013 Accepted: 25 February 2014

Published: 4 March 2014

\section{References}

1. World Health Organization: Preventing Intimate Partner and Sexual Violence Against Women: Taking Action and Generating Evidence. Geneva, Switzerland: World Health Organization; 2010:11.

2. Selic P, Pesjak K, Kersnik J: The prevalence of exposure to domestic violence and the factors associated with co-occurrence of psychological and physical violence exposure: a sample from primary care patients. BMC Public Health 2011, 11:621.

3. Kopcavar Gucek N, Svab I, Selic P: The prevalence of domestic violence in primary care patients in Slovenia in a five-year period (2005-2009). Croat Med J 2011, 52:728-734.

4. Selic P, Svab I, Kopcavar GN: How many Slovenian family practice attendees are victims of intimate partner violence? A re-evaluation cross-sectional study report. BMC Public Health 2013, 13:703.

5. Campbell J: Health consequences of intimate partner violence. Lancet 2002, 359:1331-1336.

6. Devries KM, Watts C, Yoshihama M, Kiss L, Schraiber LB, Deyessa N, Heise L, Durand J, Mbwambo J, Jansen H, Berhane Y, Ellsberg M, Garcia-Moreno C, WHO Multi-Country Study Team: Violence against women is strongly associated with suicide attempts: evidence from the WHO multi-country study on women's health and domestic violence against women. Soc Sci Med 2011, 73:79-86.

7. Vives-Cases C, Ruiz-Cantero MT, Escribà-Agüir V, Miralles JJ: The effect of intimate partner forms violence and other of violence against women on health. J Public Health 2011, 33:15-21.

8. Ansara DL, Hindin MJ: Psychosocial consequences of intimate partner violence for women and men in Canada. J Interpers Violence 2011, 26:1628-1645.

9. Mechanic MB, Weaver TL, Resick PA: Mental health consequences of intimate partner abuse: A multidimensional assessment of four different forms of abuse. Violence Against Women 2008, 14:634-654.

10. Houry D, Kaslow NJ, Thompson MP: Depressive symptoms in women experiencing intimate partner violence. J Interpers Violence 2005, 20:1467-1477.

11. Romito P, Turan JM, de Marchi M: The impact of current and past interpersonal violence on women's mental health. Soc Sci Med 2005, 60:1717-1727.

12. Houry D, Rhodes KV, Kemball RS, Click L, Cerulli C, McNutt LA, Kaslow NJ: Differences in female and male victims and perpetrators of partner violence with respect to WEB scores. J Interpers Violence 2008, 23:1041-1055.

13. Kernsmith P: Exerting power or striking back: a gendered comparison of motivations for domestic violence perpetration. Violence Vict 2005, 20:173-185.

14. Coker AL, Davis KE, Arias I, Desai S, Sanderson M, Brandt HM, Smith PH: Physical and mental health effects of intimate partner violence for men and women. Am J Prev Med 2002, 23:260-268.

15. Romans S, Forte T, Cohen MM, Du Mont J, Hyman I: Who is most at risk for intimate partner violence?: a Canadian population-based study. J Interpers Violence 2007, 22:1495-1514.
16. Whitaker DJ, Haileyesus T, Swahn M, Saltzman LS: Differences in frequency of violence and reported injury between relationships with reciprocal and nonreciprocal intimate partner violence. Am J Public Health 2007, 97:941-947.

17. Swan SC, Gambone LJ, Caldwell JE, Sullivan TP, Snow DL: A review of research on women's use of violence with male intimate partners. Violence Vict 2008, 23:301-314.

18. Breiding MJ, Black MC, Ryan GW: Prevalence and risk factors of intimate partner violence in eighteen U.S. states/territories, 2005. Am J Prev Med 2008, 34:112-118.

19. Archer J: Sex differences in physically aggressive acts between heterosexual partners: a meta-analytic review. Psychol Bull 2000, 126:651-680.

20. Próspero $M$, Kim M: Mutual partner violence: mental health symptoms among female and male victims in four racial/ethnic groups. J Interpers Violence 2009, 24:2039-2056.

21. Orcutt H, Garcia M, Pickett S: Female-perpetrated intimate partner violence and romantic attachment style in a college student sample. Violence Vict 2005, 20:287-302.

22. Ruiz-Pérez I, Plazaola-Castaño J, Del Río-Lozano M: Physical health consequences of intimate partner violence in Spanish women. Eur J Public Health 2007, 17:437-43.

23. Taft CT, Murphy CM, King LA, Dedeyn JM, Musser PH: Post-traumatic stress disorder symptomatology among partners of men in treatment for relationship abuse. J Abnorm Psychol 2005, 114:259-268.

24. Jordan CE, Campbell R, Follingstad D: Violence and women's mental health: the impact of physical, sexual, and psychological aggression. Annu Rev Clin Psychol 2010, 6:607-628.

25. Coker AL, Smith PH, Bethea L, King MR, McKeown RE: Physical health consequences of physical and psychological intimate partner violence. Arch Fam Med 2000, 9:451-457.

26. Pico-Alfonso MA, Garcia-Linares MI, Celda-Navarro N, Herbert J, Martinez M: Changes in cortisol and dehydroepiandrosterone in women victims of physical and psychological intimate partner violence. Biol Psychiatry 2004, 56:233-240

27. Bonomi AE, Anderson ML, Rivara FP, Thompson RS: Health outcomes in women with physical and sexual intimate partner violence exposure. J Womens Health (Larchmt) 2007, 16:987-997.

28. Krug EG, Mercy JA, Dahlberg LL, Zwi AB: The world report on violence and health. Lancet 2002, 360:1083-1088

29. Lown EA, Vega WA: Intimate partner violence and health: self-assessed health, chronic health, and somatic symptoms among Mexican American women. Psychosom Med 2001, 63:352-360.

30. McCauley J, Kern DE, Kolodner K, Dill L, Schroeder AF, DeChant HK, Ryden J, Bass EB, Derogatis LR: The "battering syndrome": prevalence and clinical characteristics of domestic violence in primary care internal medicine practices. Ann Intern Med 1995, 123:737-746.

31. Golding JM: Intimate partner violence as a risk factor for mental disorders: a meta-analysis. J Fam Violence 1999, 14:99-132.

32. Hathaway JE, Mucci LA, Silverman JG, Brooks DR, Mathews R, Pavlos CA: Health status and health care use of Massachusetts women reporting partner abuse. Am J Prev Med 2000, 19:302-307.

33. Coid J, Petruckevitch A, Chung WS, Richardson J, Moorey S, Feder G: Abusive experiences and psychiatric morbidity in women primary care attenders. Br J Psychiatry 2003, 183:332-339.

34. Wingood GM, DiClemente RJ, Raj A: Adverse consequences of intimate partner abuse among women in non-urban domestic violence shelters. Am J Prev Med 2000, 19:270-275.

35. Martinez-Torteya C, Bogat GA, von Eye A, Levendosky AA, Davidson WS 2nd: Women's appraisals of intimate partner violence stressfulness and their relationship to depressive and posttraumatic stress disorder symptoms. Violence Vict 2009, 24:707-722.

36. Perez $\mathrm{S}$, Johnson DM, Wright CV: The attenuating effect of empowerment on IPV-related PTSD symptoms in battered women living in domestic violence shelters. Violence Against Women 2012, 18:102-17.

37. Lövestad S, Krantz G: Men's and women's exposure and perpetration of partner violence: an epidemiological study from Sweden. BMC Public Health 2012, 12:945.

38. Kimmel MS: "Gender symmetry" in domestic violence: a substantive and methodological research review. Violence Against Women 2002, 8:1332-1363.

39. Ruiz-Pérez I, Plazaola-Castaño J: Intimate partner violence and mental health consequences in women attending family practice in Spain. Psychosom Med 2005, 67:791-797. 
40. Jansen HAFM, Watts C, Ellsberg M, Heise L, Garcia-Moreno C: Interviewer training in the WHO Multi-country Study on Women's Health and Domestic Violence. Violence Against Women 2004, 10:831-849.

41. Selic P, Pesjak K, Kopcavar-Gucek N, Kersnik J: Factors that increase likelihood of violence in the family and seeking for help at family practitioner. Pilot study about violence in the family. (English summary). Zdrav Vestn 2008, 77:505-510.

42. Shakil A, Donald S, Sinacore JM, Krepcho M: Validation of the HITS domestic violence screening tool with males. Fam Med 2005, 37:193-198.

43. Feder G, Ramsay J, Dunne D, Rose M, Arsene C, Norman R, Kuntze S, Spencer A, Bacchus L, Hague G, Warburton A, Taket A: How far does screening women for domestic (partner) violence in different health-care settings meet criteria for a screening programme? Systematic reviews of nine UK National Screening Committee criteria. Health Technol Assess 2009 13(iii-iv, xi-xiii):1-113. 137-347.

44. Ellsberg M, Jansen HA, Heise L, Watts CH, Garcia-Moreno C: Intimate partner violence and women's physical and mental health in the WHO multi-country study on women's health and domestic violence: an observational study. Lancet 2008, 371:1165-1172.

45. Próspero M: Mental health symptoms among male victims of partner violence. Am J Mens Health 2007, 1:269-277.

46. Johnson MP: Conflict and control: gender symmetry and asymmetry in domestic violence. Violence Against Women 2006, 12:1003-1018.

47. Vos T, Astbury J, Piers LS, Magnus A, Heenan M, Stanley L, Walker L, Webster $K$ : Measuring the impact of intimate partner violence on the health of women in Victoria, Australia. Bull World Health Organ 2006, 84:739-744.

48. Avdibegović $E$, Sinanović O: Consequences of domestic violence on women's mental health in Bosnia and Herzegovina. Croat Med J 2006, 47:730-741.

49. Carbone-López K, Kruttschnitt C, Macmillan R: Patterns of intimate partner violence and their associations with physical health, psychological distress, and substance use. Public Health Rep 2006, 121:382-392.

50. Ludermir AB, Schraiber LB, D'Oliveira AFPL, França-Junior I, Jansen HA: Violence against women by their intimate partner and common mental disorders. Soc Sci Med 2008, 66:1008-1018.

51. Pico-Alfonso MA, Garcia-Linares IM, Celda-Navarro N, Blasco-Ros C, Echeburúa E, Martinez M: The impact of physical, psychological, and sexual intimate male partner violence on women's mental health: depressive symptoms, posttraumatic stress disorder, state anxiety, and suicide. J Womens Health (Larchmt) 2006, 15:599-611.

52. Wong JYH, Tiwari A, Fong DYT, Humphreys J, Bullock L: Depression among women experiencing intimate partner violence in a Chinese community. Nurs Res 2011, 60:58-65.

53. Zlotnick C, Johnson DM, Kohn R: Intimate partner violence and long-term psychosocial functioning in a national sample of American women. $J$ Interpers Violence 2006, 21:262-275.

54. Blasco-Ros C, Sánchez-Lorente S, Martinez M: Recovery from depressive symptoms, state anxiety and post-traumatic stress disorder in women exposed to physical and psychological, but not to psychological intimate partner violence alone: a longitudinal study. BMC Psychiatry 2010, 10:98.

55. Chandra PS, Satyanarayana VA, Carey MP: Women reporting intimate partner violence in India: associations with PTSD and depressive symptoms. Arch Womens Ment Health 2009, 12:203-209.

56. Ehrensaft MK, Moffitt TE, Caspi A: Is domestic violence followed by an increased risk of psychiatric disorders among women but not among men? A longitudinal cohort study. Am J Psychiatry 2006, 163:885-892.

57. Schneider R, Burnette ML, Ilgen MA, Timko C: Prevalence and correlates of intimate partner violence victimization among men and women entering substance use disorder treatment. Violence Vict 2009, 24:744-756.

58. Woods SJ, Hall RJ, Campbell JC, Angott DM: Physical health and posttraumatic stress disorder symptoms in women experiencing intimate partner violence. J Midwifery Womens Health 2008, 53:538-546.

59. Nerøien IA, Schei B: Partner violence and health: results from the first national study on violence against women in Norway. Scand J Public Health 2008, 36:161-168.

60. Gerber MR, Wittenberg E, Ganz ML, Williams CM, McCloskey LA: Intimate partner violence exposure and change in women's physical symptoms over time. J Gen Intern Med 2008, 23:64-69.

61. Angst J, Gamma A, Gastpar M, Lépine JP, Mendlewicz J, Tylee A: Gender differences in depression. Eur Arch Psychiatry Clin Neurosci 2002, 252:201-9.
62. Gilchrist G, Gunn J: Observational studies of depression in primary care: what do we know? BMC Fam Pract 2007, 11:8-28.

63. Kessler RC, Keller MB, Wittchen HU: The epidemiology of generalized anxiety disorder. Psychiatr Clin North Am 2001, 24:19-39.

64. Klemenc-Ketis Z, Kersnik J, Tratnik E: The presence of anxiety and depression in the adult population of family practice patients with chronic diseases. Zdrav Var 2009, 48:170-6.

65. Employment Service of Slovenia: The rate of registered unemployment. http://www.ess.gov.si/trg_dela/trg_dela_v_stevilkah/ stopnja_registrirane_brezposelnosti (accessed on October 29, 2013).

66. Jewkes R: Intimate partner violence: causes and prevention. Lancet 2002, 359:1423-9.

67. Socioeconomic Characteristics of Population, Slovenia, 1 January 2012 - Final Data. First Release. Statistical Office of the Republic of Slovenia. http://www stat.si/eng/novica_prikazi.aspx?id=5411 (accessed on October 29, 2013).

68. Abramsky T, Watts CH, Garcia-Moreno C, Devries K, Kiss L, Ellsberg M, Jansen $H A$, Heise L: What factors are associated with recent intimate partner violence? Findings from the WHO multi-country study on women's health and domestic violence. BMC Public Health 2011, 11:109.

69. Svab I, Petek Ster M, Kersnik J, Zivcec Kalan G, Car J: A cross sectional study of performance of Slovene general practitioners (English summary). Zdrav Var 2005, 44:183-192.

70. Klemenc-Ketis Z, Kersnik J, Ojstersek J: Perceived difficulties in managing ethical problems in family practice in Slovenia: cross-sectional study. Croat Med J 2008, 49:799-806.

doi:10.1186/1471-2458-14-223

Cite this article as: Selic et al:: A cross-sectional study identifying the pattern of factors related to psychological intimate partner violence exposure in Slovenian family practice attendees: what hurt them the most. BMC Public Health 2014 14:223.

\section{Submit your next manuscript to BioMed Central and take full advantage of:}

- Convenient online submission

- Thorough peer review

- No space constraints or color figure charges

- Immediate publication on acceptance

- Inclusion in PubMed, CAS, Scopus and Google Scholar

- Research which is freely available for redistribution 